\title{
Factors triggering epileptic seizures in patients over 50 years
}

\author{
Serkan Demir ${ }^{1 *}$, Rifat Erdem Togrol ${ }^{1}$, Ali Riza Sonkaya ${ }^{2}$, Mustafa Tansel Kendirli ${ }^{1}$, Semih \\ Alay $^{3}$, Tugba Yanar Celik ${ }^{4}$, Sakir Delil ${ }^{1}$, Mehmet Fatih Ozdag ${ }^{1}$
}

\section{Abstract}

Objective: In this study the factors that trigger the seizures in epileptic patients over the age of 50 were investigated and the frequencies of seizures were analysed regarding to different age, gender, type of seizure and etiological groups.

Material and Methods: For this purpose, 387 patients were included in the studies who were admitted to neurology outpatient clinic with the diagnosis of epilepsy. The patients are divided into groups based on those characteristics: male / female, generalized seizure / partial seizure, age between 50 and 65 / age over 65, they were evaluated in terms of seizure triggers.

Results: The most common precipitating factor in all groups were found as stress (37\%), sleeplessness $(27 \%)$ and forgetting to take the medication $(20 \%) .31 \%$ of the patients were on Carbamazepine, $21 \%$ were on Levetiracetam and 19\% were on Valproic Asid. The most common etiological causes were identified as idiopathic $(39 \%)$, post stroke $(24 \%)$ and dementia (15\%). Regarding the triggering factor, some statistically significant differences were found between the following groups and control groups; the group with patients between the age 50 and 65: stress, fatigue, waking and sleeping; the group with female patients: sleeplessness; the group with the generalized seizures: alcohol and sleep.

Conclusion: In conclusion $68 \%$ of our patients complained about at least one seizure precipitant and the most common precipitants were stress, sleeplessness and missing dose of medication. In this study, age between 50 and 65 group is more affected by triggers.

Keywords: Epilepsy, Seizure precipitants, Stress, Sleeplessness, Missing

\section{Introduction}

Epileptic seizure is the unavoidable overactivity of a part or the whole of the central nervous system (CNS) as a result of sudden, paroxysmal, high-voltage electrical discharges (1). If the loss of consciousness, abnormal sensory or motor activity and behavioural dysfunction that is seen during a seizure is of a repetitive nature, the term 'epilepsy' is used (2). Epilepsy is a common health problem in the whole world.

Neurological problems are seen fairly commonly in patients of the geriatric age group. Epilepsy is the most common neurological disease after cerebrovascular disease and dementia in the elderly. Since it is projected that by the year of $2050,20 \%$ of the world's population will be the aging, it is necessary to focus more seriously on diseases of elderly $(6,7)$.
The studies done in patients from other age groups should also be done in older patients; elderly epileptics are equally entitled to research on diagnosis and treatment of epileptic seizures (8). Many studies have been done on the factors triggering seizures and therapy in children and young adults and many endogenous (stress, fatigue, fever, menstrual cycle, sleep, etc.) and exogenous (alcohol, caffeine, eat, sleep, flickering light, temperature, humidity etc.) triggers have been defined. Yet, there aren't enough studies on these issues in the elderly (9). Information on this subject for epileptic people over 50 years is mostly based on data from personal experiences or claims. In this article, we are presenting the results of the survey study which we think is addressing these missing issues, and want to share the results to attract attention to the issue.

Received: 31-10-2015, Accepted 22-12-2015, Available Online 15-01-2016

1 Gulhane Military Medical Academy Haydarpasa Training Hospital Department of Neurology

2 Erzurum Mareşal Cakmak Military Hospital, Department of Neurology Erzurum, Turkey

3 Gulhane Military Medical Academy Ankara, Department of Neurology Ankara, Turkey

4 Malkara State Hospital department of Neurology, Malkara, Turkey

*Corresponding Author: Zeynab Qasemiyan Khojaste E-mail: namdarh@tbzmed.ac.ir 


\section{Material and Methods}

In this study, 387 patients over 50 years of age, who were evaluated between February 2013-June 2013 in GATA Haydarpaşa Training Hospital Neurology Department Outpatient Policlinic, GATA Ankara Neurology Department Clinic, Cerrahpaşa Faculty of Medicine Neurology Department Epilepsy Policlinic and Haydarpaşa Numune Training and Research Hospital Neurology Department Epilepsy Outpatient Policlinic, who have been diagnosed as having epilepsy by a neurologist, who were over 50 years of age, and who have been followed up for more than 6 months were included. These patients were evaluated for the "factors that trigger seizures in epileptic patients over the age of 50". Metabolic disorders, post-infectious causes, fever and other causes that may present with symptomatic seizures that last less than six months were excluded from the study. To investigate this issue, a random sample of 387 epilepsy patient volunteers selected from those being followed up in the outpatient departments were asked to complete the screening questionnaire. While developing the instrument, a pre-test consisting of open-ended questions was administered to 30 patients in order to determine the factors that determine the factors that trigger the seizures. The information obtained from these patients was used to identify the triggering factors and these factors were added to the survey. An open-ended item was also included; thus nothing was left out and all the factors could be evaluated.

\section{Statistical method:}

Statistical analysis of the study was carried out by using the SPSS 18:00 program. Qualitative variables were summarized with frequency and percent values, numerical variables were summarized by mean \pm standard deviation values. Basic topics investigated in this study are the age group with the triggering factors, age of onset of seizures, sex, disease, type of seizure types. The relationship between all variables was investigated. To investigate this relation, chi-square test, which is the statistical test to investigate the difference between qualitative variables, was used. To investigate the relation between the treatment groups and the variables evaluated, Spearman's rho coefficient was used. Since the types of treatment and the types of disease variables were more than two level, linear association test statistic, which is a specialized version of Chi-squared test was used.

Our study was given "ethical approval" by the GATA Haydarpasa Training Hospital Non-Invasive Clinical Research Ethics Committee with project number 2013-14 in the 13th session on February 28, 2013.

\section{Results}

387 patients were included in the study and $52 \%$ were men. 59\% were between 50-65 years, 54\% were patients whose seizures started after the age of 50 and $52 \%$ had partial seizures. (Table 1 ). The $31 \%$ of the patients in the study were using carbamazepine as therapeutic, and $21 \%$ levetiresetam $19 \%$ valproic acid and $\% 9$ fenitoin for epilepsy treatment (Table 2).

Table 1: Sex, age group, age of seizure onset and type of seizures descriptive statistics

\begin{tabular}{llcc}
\hline Groups & & $\mathbf{n}$ & $\mathbf{\%}$ \\
Sex & Male & 201 & $52 \%$ \\
Age group & Female & 186 & $48 \%$ \\
& $>$ 65 years & 160 & $41 \%$ \\
Age of seizures & 50-65 years old & 227 & $59 \%$ \\
& <age 50 years & 209 & $54 \%$ \\
Type of seizure & >50 years & 178 & $46 \%$ \\
& Generalized & 184 & $48 \%$ \\
& Partial & 203 & $52 \%$ \\
\hline
\end{tabular}

Table 2. Treatment type variables descriptive statistics

\begin{tabular}{lll}
\hline Drugs type & $\mathbf{n}$ & $\mathbf{\%}$ \\
Carbamazepine & 119 & 31 \\
Levetirecetam & 83 & 21 \\
Valproic Acid & 75 & 19 \\
Fenitoin & 35 & 9 \\
\hline
\end{tabular}

Idiopathic causes were found in $39 \%$ of patients, cerebrovascular diseases in $24 \%$, and dementia was present in $15 \%$ (Table 3).

Table 3. Etiology variables summary statistics

\begin{tabular}{lcc} 
Disease & n & \% \\
\hline İdiopathic & 151 & $39 \%$ \\
Cerebrovascular disease & 92 & $24 \%$ \\
Dementia & 57 & $15 \%$ \\
Brain tumour & 49 & $13 \%$ \\
Post-traumatic & 38 & $10 \%$ \\
\hline
\end{tabular}

At this point $68 \%$ of the participants $(n=122)$ reported at least one triggering factor for seizures. At Table 4 all factor that are thought to trigger seizures and their frequencies are listed. $37 \%$ of the patients have reported seizures triggered by stress. Insomnia was a triggering factor in $27 \%$, while missing doses was mentioned as a triggering factor in $20 \%$.

Table 4 Seizure Triggers

\begin{tabular}{lcc} 
Triggering factor & $\mathbf{n}$ & $\mathbf{\%}$ \\
\hline Hunger & 27 & $7 \%$ \\
Insomnia & 104 & $27 \%$ \\
Sleep & 36 & $9 \%$ \\
Waking & 6 & $2 \%$ \\
Stress & 145 & $37 \%$ \\
Weather Changes & 12 & $3 \%$ \\
Heat & 4 & $1 \%$ \\
(high sound) & 4 & $1 \%$ \\
Photosensitivity & 6 & $2 \%$ \\
Missing doses & 79 & $20 \%$ \\
Fatigue & 45 & $12 \%$ \\
Alcohol & 21 & $5 \%$ \\
\hline
\end{tabular}




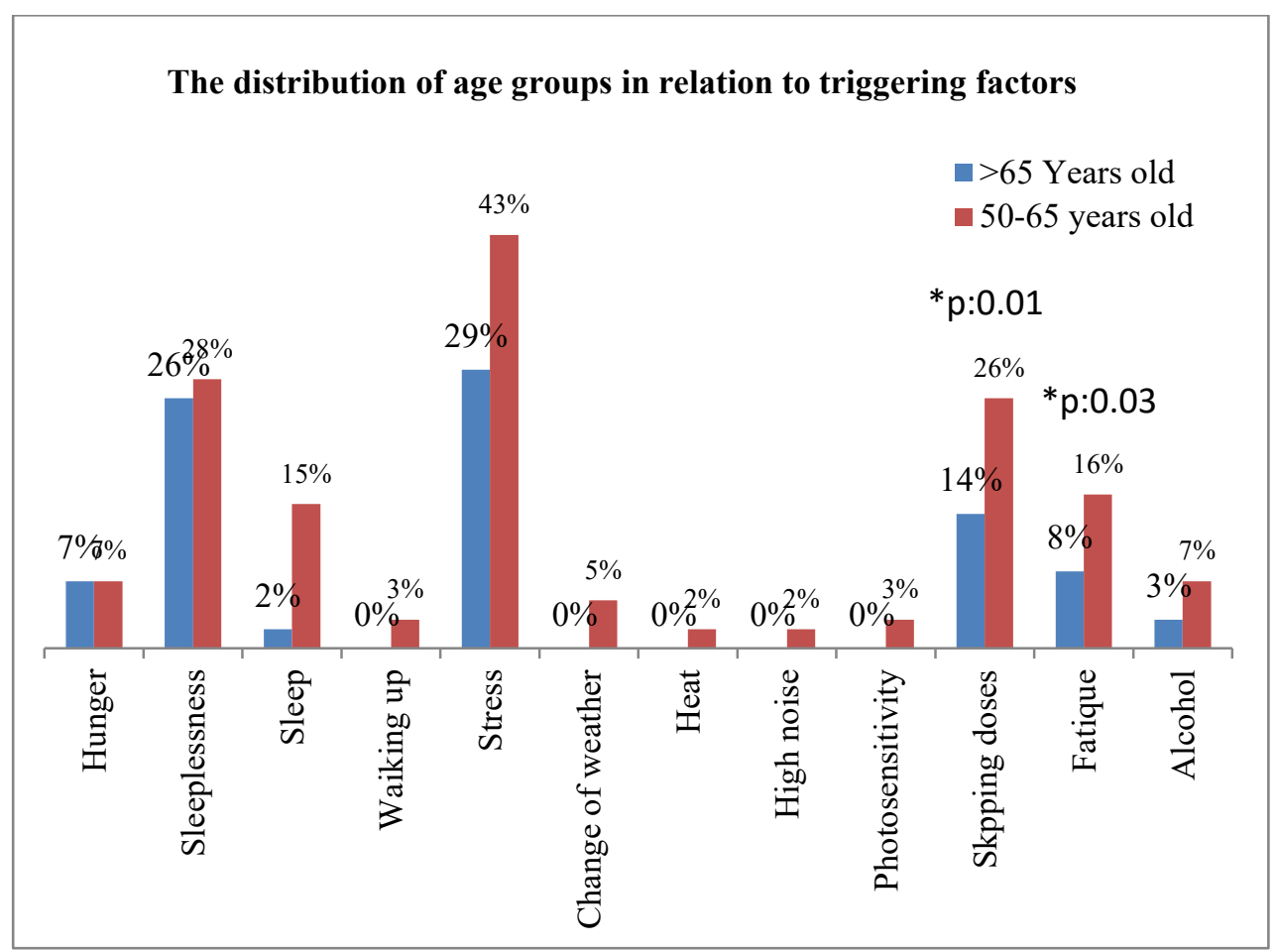

Figure 1: The distribution of triggering variables in relation to age

Comparing sex groups, females were found to have significantly more seizures in case of insomnia $(p=$ 0.039) (Figure 2).

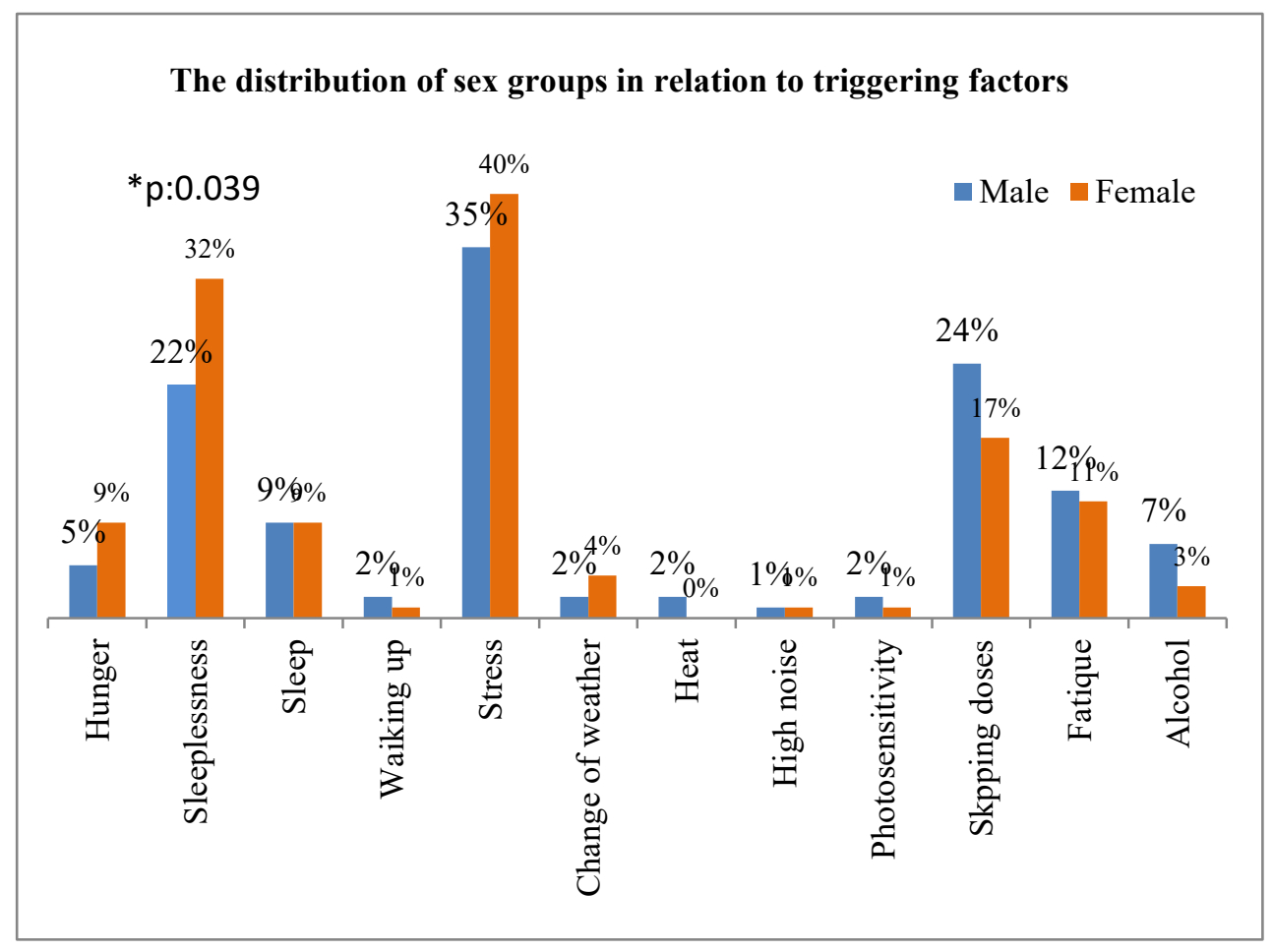

Figure 2: The distribution of triggering variables in relation to sex groups 
In patients with generalized seizure types, sleep $(p=0.006)$ and alcohol $(p=0.000)$ were found to trigger seizures at a significantly higher frequency. (Figure 3 ).

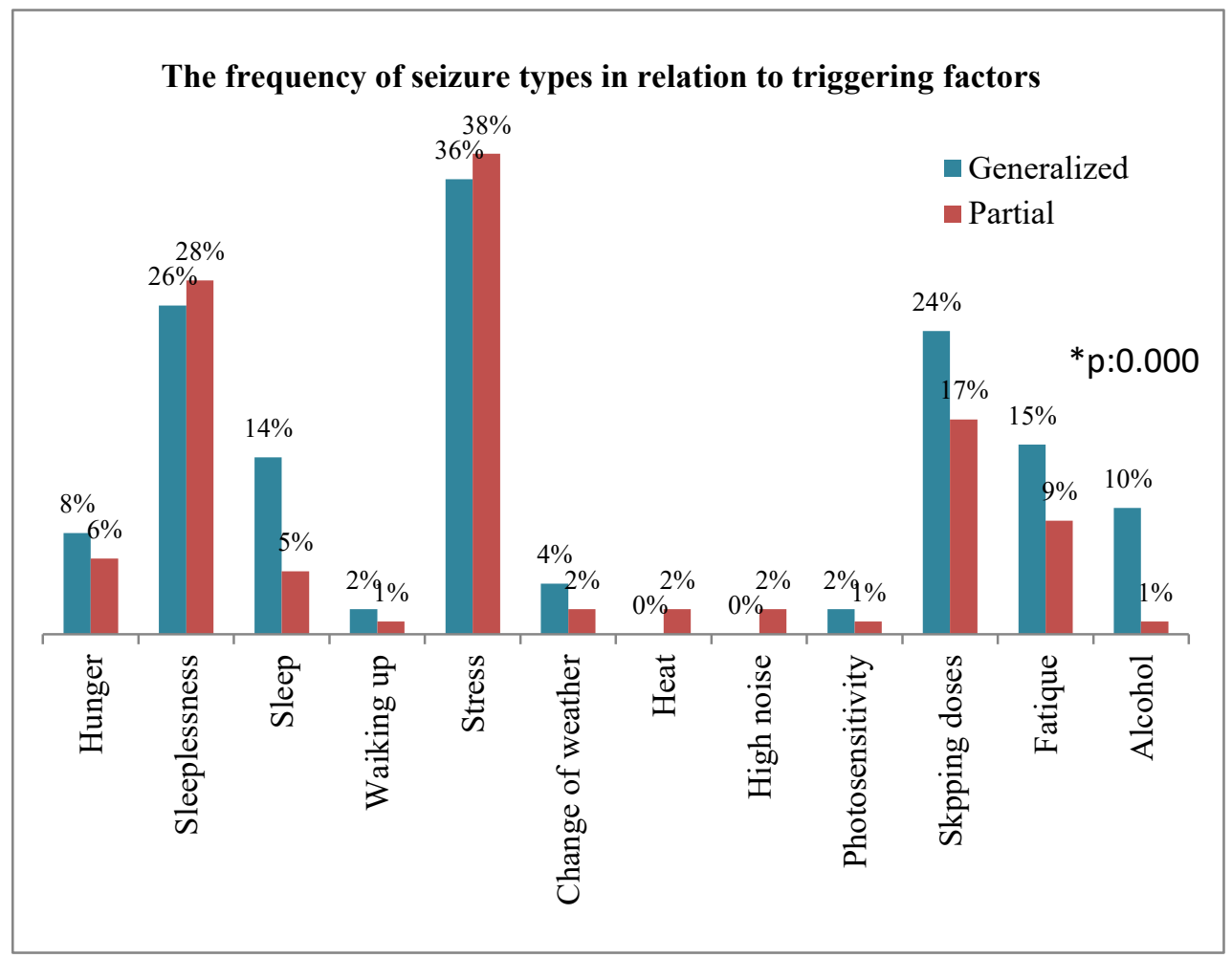

Figure 3: The frequency of seizure types in relation to triggering factors

When the two age groups were compared, patients in the 50-65 years age group had significantly more seizures during sleep $(\mathrm{p}=0.000)$, while waking up $(\mathrm{p}$ $=0.038)$, with stress $(\mathrm{p}=0.006)$, weather changes $(\mathrm{p}=$ $0.003)$, photosensitivity $(\mathrm{p}=0.038)$, missing doses $(\mathrm{p}$ $=0.013)$ and fatigue $(\mathrm{p}=0.033)$. Additionally, patients in the 50-65 years age group had significantly more seizures. In general, triggering factors had a significantly higher probability to trigger seizures in the 50-65 age group. (Figure 1).

\section{Discussion}

Epileptic seizure is the unavoidable overactivity of the whole or a part of the central nervous system (CNS) as a result of sudden, paroxysmal, high-voltage electrical discharges (1). Its incidence increases again after the age of 50 years and after 65 years the incidence of epilepsy reaches the highest incidence of all age groups. The incidence of epilepsy is at its lowest values in the $40 \mathrm{~s}(30-40 / 100,000)$, its incidence rapidly increases in the $50 \mathrm{~s}$. In ages around $80 \mathrm{~s}$, the average value is at the 140-160/100,000 level (6-8).

Although definitions vary according to the resources, the term "elderly" is mainly used for individuals over 65 years.
Meanwhile, after the age of 50 years, the incidence of epilepsy increases along with the increasing incidence of many systemic diseases. In our study, we described pre-senile age group as the patients between 50-65 years of age (5-8).

It is not easy to diagnose epilepsy in elderly patients. Usually a generally reliable story cannot be obtained from these patients, and these patients may have different seizures that are not observed by their relatives or that may be confused with or misinterpreted as other conditions. Epilepsy may present very different from young people in the elderly (9).

The etiology of epilepsy in our study was; idiopathic in $39 \%$, cerebrovascular disease in $24 \%$, dementia in $15 \%$. Compared to the literature, our higher rate of idiopathic epilepsies may be due to undiagnosed other etiologies (e.g. meningioma, dementia, or head trauma overlooked in medical history etc.) and also be due to cryptogenic epilepsy patients been considered in this group. There are studies suggesting Alzheimer's disease as a cause of late-onset epilepsy with no identified etiology (10). 
The diagnosis of epilepsy in older patients with different presentations may also be difficult because of the patient's current disease and seizures. These patients may respond to low-dose antiepileptic agent. Side effects in a wide range may occur, including sedation, tremor and cognitive disorders, depending on the patient and the AEDs used. The combination therapy should be avoided if possible, due to combination therapies may increase side effects (11). Since elderly patients often use other drugs (antihypertensive, antidiabetic, antidementia, etc.), agents with lower drug interactions, drugs that do not bind to proteins and do enzyme induction should be preferred. Cognitive and psychological effects should be positive. In this age group, the seizures can be controlled with proper treatment at correct doses in $70 \%$ of the patients $(11,12)$.

The most common agents used were carbamazepine (31\%), levetiracetam (21\%) and valproic acid (19\%). The relatively high frequency of partial seizures may have been a reason for the neurologists' choice of carbamazepine. The possibility to follow blood drug levels of carbamazepine and valproate, and the long experience related to these agents may be other reasons for their selection of these agents. However, unlike the literature, the second most preferred drug is levetiracetam. The reason for the selection of this drug may be the low drug interactions, its side effect profile being lower than other AEDs, and easy dose titration, with going up to high doses in a relatively short time (13).

$68 \%$ of the participants in our study reported at least one seizure triggering factor. Results of different studies has revealed a seizure triggering factor (at least one) at a ratio between 53-86.6\% (14-18).

Stress is an automatic response when a condition or force that exceeds the person's ability to deal with is detected. Fear, anxiety and concern are moods that are the reflections of stress in everyday life (19-21). Epilepsy is one of the common areas of study for different disciplines such as neurology, psychiatry, neurosurgery and pediatrics. Specifically, many studies have been done on the neuropsychological aspects of epilepsy in the last century (22-27). Meanwhile, individuals are exposed to stress factor more at old age than young individuals due to affective problems due to physical challenges, loss of self-confidence, feeling helpless, loneliness, hopelessness, inability to fulfill one's responsibilities, and social challenges such as those due to retirement, loss of productivity and economic difficulties. Jalava et al. have demonstrated in their 35-year follow study that patients with epilepsy have a 4 -fold increased risk of developing psychiatric disease and are sensitive to stress than normal individuals (28). On the other hand, the relationship between stress and seizures is usually accepted by clinical experience and Nancy et al. have demonstrated in the work they have done that stress is a factor that triggers seizures (29). In their study on the quality of life of epilepsy patients, Baker et al. have shown that stressful experiences tend to increase seizure frequency. Again it was concluded in this study that the mental and physical fatigue caused by stress results in an increase in seizure frequency (30). Other studies demonstrating that seizures may be triggered by stress are also present (15,17,31-35). Although quite a number of hypotheses have been put forward on how stress triggers seizures, the exact mechanism has not yet been clearly explained (36).

There is an interaction between sleep and epilepsy. The effect of sleep on epilepsy and the effects of epilepsy on sleep, has been intriguing scientists for many years, and despite a number of studies conducted on the subject, it is still not yet fully clear $(37,38)$. In particular, the occurrence of SUDEP usually happening during sleep has increased the interest on the relation of sleep and epilepsy. Especially childhood epileptic syndromes are known to have close relationship with sleep.

In our study, the second most triggering factor was found to be insomnia with $27 \%$. In patients between 50-65 years of age and in women insomnia was found to trigger seizures significantly. At the same time, stress is also a cause of insomnia in women and in the elderly. Stress and insomnia are closely related to each other as triggering factors. Insomnia also may create stress (39). In studies comparing the two sexes, insomnia problem was more prevalent in women than men, similar to our study. Women may not spend enough time to sleep like men, due to their tempo of business life and their responsibility associated with family business and housework. According to the data from the US National Sleep Foundation, women aged 30-60 years allocate only 6 hours 41 minutes to sleep. To be a woman and to have insomnia are associated with each other $(40$

Although skipping doses of medication is not counted among endogenous or exogenous triggers, it is one of most common causes of status epilepticus. Antiepileptic drugs are effective with a particular concentration in the blood and instant withdrawal or decrease in concentration is thought to trigger seizures. Usually studies that investigate seizure triggers do not evaluate skipping doses; we wanted to address this issue with the result of our study. In this study, skipping doses was found to be the third most common triggering factor with $20 \%$.

In conclusion, there is at least one trigger for seizures in $68 \%$ of our patients. The most common seizure triggers were found to be stress with $37 \%$, insomnia with $27 \%$ and skipping doses with $20 \%$. Etiological causes were, idiopathic $15 \%$, Cerebrovascular disease $24 \%$, dementia 39\%, brain tumor $13 \%$ and posttraumatic $10 \%$ respectively. Most commonly used three agents were identified as; carbamazepine $31 \%$, 
valproic acid $19 \%$ and levetiracetam $21 \%$. When our study groups were evaluated, the effect of seizure triggering factors are statistically significant in the group whose seizures started before the age of 50 and the group with seizures starting 50-65 years of age.

Conflict of Interest: The authors declare no potential conflicts of interest with respect to the research, authorship, and/or publication of this article. The first case was presented as poster presentation at the American Academy of Neurology 67th Annual Meeting, 18-25 April 2015, Washington DC, USA.

\section{References}

1. Shovon S.D. Epidemiology, classification, natural history and genetics of epilepsy. Lancet 1990;336: $93-96$

2. Banerjee PN, Filippi D, Hauser WA. The descriptive epidemiology of epilepsy. Epilepsy Research 2009; 85:3145

3. Hauser WA. Seizure disorders: the chances with age Epilepsia 1992;33(suppl4):6-7

4. Spector S, Cull C, Goldstein LH. Seizure precipitants and perceived self-control of seizures in adults with poorlycontrolled epilepsy. Epilepsy Research 2000; 38; 207- 216

5. Courte DL, Breteler MM, Meinardi $\mathrm{H}$, Hauser A, Hoffman A. Prevelance of epilepsy in the elderly: the Rotterdam study: Epilepsia 1996;37:141-147

6. Stephen L, Brodie M. Epilepsy in elderly people. The Lancet 2000;355:1441-1446

7. DeToledo JC. Changing presentation of seizeures with aging: Clinical and etiological factors. Gerontology 1999;45:329-335

8. Cloyd J, Hauser W, Towne A, Ramsay R, Mattson R, Gliam F, Walczak T. Epidemiological and medical aspects of epilepsy in the elderly. Epilepsy Research 2006;68:39-48

9. Tascılar NF, Bozdemır H, Aslan K, Sarıca Y, Seydaolu G Yaşlı epilepsi hastalarında elektroensefalografinin yeri. Epilepsi 2006;12(1):32-41

10. Mendez MF, Catanzaro P, Doss RC. Seizures in Alzheimer's disease: Clinicopathologic study. J Geriatr Psychiatry Neurol 1994;7:230-233

11. Wilmore LJ. Management of epilepsy in the elderly Epilepsia 1996;37(6):23-33

12. Stephen L, Brodie M. Epilepsy in elderly people. The Lancet 2000;355:1441-1446

13. Berkovic SF: Treatment with anti- epileptic drugs. Aust Fam Physician. 2005; 34: 1017-1020.

14. Dorothee GA. Provaked and reflex seizures: Suprising and common? Epilepsia 2012; 53(4):105-112
15. Pinikahana J, Dono J. Age and gender differences in initial symptoms and precipitant factors of epileptic seizures: An Australian study. Epilepsy and Behaviour 2009; 16: 231239

16. Lunardi MDS, Sukys-Claudino L, Guarnieri R, Walz R, Lin K. Seizure precipitants and inhibiting factors in mesial temporal lobe epilepsy. Journal of the neurological sciences 2011;308:21-24

17. Spector S, Cull C,Goldstein L. Seizure precipitants and perceived self-control of seizures in adults with poorlycontrolled epilepsy. Epilepsy Research 2000;38:207-216

18. Fang PC, Chen YC, Lee IC. Seizure precipitants in children with intractable epilepsy. Brain \& Development 2008; 30 527-532

19. Oto R, Apak I, Arslan S, Yavavlı A, Altındağ A, Karaca EE. Epilepsinin psikososyal etkileri. Klinik Psikyatri Dergisi 2004; 7:210-214

20. Baker GA, Jacoby A, Buck D. Quality of life people with epilepsy. Epilepsia 1997; 38: 353-362

21. Nancy RT, Gay D. Stress as a risk factor for seizure among adults with epilepsy. Epilepsia 2008; 43: 456-468

22. Chadwick D. Epilepsy. J Neurol Neurosurg Psychiatry. 1994;57(3):264-77

23. Swinkels WA, Kuyk J, van Dyck R, Spinhoven P. Psychiatric comorbidity in epilepsy. Epilepsy Behav. 2005;7:37-50.

24. Sachdev P. Schizophrenia-like psychosis and epilepsy: the status of the association. Am J Psychiatry. 1998;155:325336.

25. Kristensen O, Sindrup EH. Psychomotor epilepsy and psychosis. I. Physical aspects. Acta Neurol Scand. 1978;57:361-369

26. Slater E, Beard AW, Glithero E. The schizophrenialike psychoses of epilepsy. Br J Psychiatry. 1963;109:95-150

27. Suurmeijer TP, Reuvekamp MF, Aldenkamp BP. Social functioning, psychological functioning, and quality of, life in epilepsy. Epilepsia 2001;42(9):1160-1168

28. Jalava $\mathrm{M}$, Sillanpaa $\mathrm{M}$. Concurrent illness in adult with childhood-onset epilepsy: a population-based 35 year follow up study. Epilepsia 1996;1155-1163

29. Nancy RT, Gay D. Stress as a risk factor for seizure among adults with epilepsy. Epilepsia 2008; 43: 456-468Silber MH. Sleep Disorders. Neurol Clin 2001;1,173-186

30. Baker GA, Jacoby A, Buck D. Quality of life people with epilepsy. Epilepsia 1997; 38: 353-362

31. Nakken KO, Solaas MH, Kjeldsen MJ. Which seizures precitating factors do patients with epilepsy most frequently report? Epilepsy Behav 2005;6:185-189

32.

Frucht MM, Quigg M, Schwazer C. Distrubituion of seizure precipitants among epilepsy syndromes. Epilepsia 2000;41:1534-1539

33. Sperling MR, Schilling CA, Glosser D, Tracy JI. Selfperception of seizure precipitants and their relation the anxiety level, depression, and health locus of control in epilepsy. Seizure 2008;17:302-307 
34. Hart YM, Shorvon SD. The Nature Of Epilepsy In Teh General Population: I: characteristics of of patients receiving medication for epilpsy. Epilepsy Res 1995; 21:4349

35. Cull CA, Fowler M, Brown SW. Perceived self control of seizures in young people with epilpsy. Seizure 1996;5:131138

36.

Friedman RA, Cacheaux LP, Ivens S, Kaufer D. Elucidating the complex interactions between stres and epileptogenic pathways. Cardiovasc Psychiatry Neurol. 2011; 10; 1-8
37.

Salgado PC, Souza EA. Quality of life in epilepsy and perception of seizure control. Arg Neuropsiquiatr 2001; 59: $537-40$.

38. Birbeck GL, Ron D, Hays RD et al. Seizure reduction and quality of life improvements in people with epilepsy. Epilepsia 2002; 43:535-8.

39. Silber MH. Sleep Disorders. Neurol Clin 2001;1,173-186

40. www.sleepfoundatiom.org Women and Sleep

Copyright (C) 2014 The Author(s); This is an open-access article distributed under the terms of the Creative Commons Attribution License (http://creativecommons.org/licenses/by/4.0), which permits unrestricted use, distribution, and reproduction in any medium, provided the original work is properlv cited. All Rights reserved bv international iournal of Medical Science and Discoverv.

Medical Science and Discovery, 2016; 3(1): 40-6 